\title{
SARS-CoV-2 in pre-existing autoimmune myasthenia gravis: An institutional experience
}

\author{
Nitisha Goyal, Rahul Jain, Dinesh Chouksey, Ajoy Sodani \\ Department of Neurology, Sri Aurobindo Medical College and Post Graduate Institute, Indore, \\ Madhya Pradesh, India
}

\begin{abstract}
The impact of SARS-CoV-2 on pre-existing chronic neuromuscular junction disorders like myasthenia gravis (MG) is not known. We report three patients with pre-existing acetylcholine receptor autoantibody-positive myasthenia gravis who were infected with SARS-CoV-2. We observed the clinical course of these patients during hospitalization, none of the three patients had an exacerbation of peripheral myasthenia syndromes like ptosis, extra-ocular muscle weakness, bulbar or limb weakness during hospitalization. Therapy for MG was not altered during hospitalization for any of the patients. While two of the patients had a favorable outcome, one succumbed to the complications of SARS-CoV-2. Our findings suggest that the clinical course of MG remains unaffected during course, however outcome is variable depending on severity of SARS-CoV-2. Further large observations are needed to define best management and treatment principals and determinants of outcomes in this unique patient population of co-occurrence of SARS-CoV-2 and myasthenia gravis.
\end{abstract}

Keywords: COVID-19, myasthenia gravis, neuroimmunology, neuromuscular disorders, immunosuppression

\section{INTRODUCTION}

SARS-CoV-2 infection has caused a global health crisis and apart from respiratory system involvement, it has been found to significantly affect the nervous system- directly or indirectly [1-3]. The impact of SARS-CoV-2 on pre-existing chronic neuromuscular junction like myasthenia gravis (MG) is not known. We describe the clinical course and outcomes of three patients with pre-existing MG, infected with SARS-CoV-2.

\section{MATERIALS AND METHODS}

This observational study was carried out in the Department of Neurology in a teaching hospital in central India from $15^{\text {th }}$ September 2020 to $15^{\text {th }}$ November 2020 . The patients included were known or pre-existing patients of autoimmune Myasthenia Gravis with current hospital admission for SARS-CoV-2 infection. They were diagnosed positive for SARS-CoV-2 based on positive nasopharyngeal swab RT-PCR, in the setting of clinical symptoms and supportive CT chest findings. The diagnosis of autoimmune MG was confirmed by reviewing the symptoms, autoantibody status and electrophysiological testing done at the time of receiving the diagnosis.

\section{CASES PRESENTATION}

\section{Patient 1}

71 years old male patient, hypothyroid was diagnosed as autoimmune MG 8 months prior. He was on Tab Omnacortil $20 \mathrm{mg}$ daily, Tab Pyri- 
dostigmine $60 \mathrm{mg}$ twice daily and Tab Mycophenolate Mofetil $360 \mathrm{mg}$ twice daily. He had a relatively stable course during hospitalization and was treated with Remdesvir therapy. He needed intermittent oxygen inhalation at 2-4 litres/minute flow rate. He had no exacerbation of peripheral myasthenia syndromes like ptosis, extra-ocular muscle weakness, bulbar or limb weakness during hospitalization. Therapy for MG was not altered during hospitalization. He was discharged within 7 days of admission.

\section{Patient 2}

63-years-old male, diabetic and hypothyroid patient was diagnosed as autoimmune MG 52 months prior. His symptoms were well controlled on Tab Azathioprine 50mg twice daily and Tab Pyridostigmine $60 \mathrm{mg}$ twice a day. He developed fever, cough and throat pain and testing showed he was positive for SARS-CoV-2. He was admitted to the hospital on day 6 of onset of symptoms and needed high flow oxygen via non re-breathing mask for maintaining arterial oxygen saturation.
As he developed increased respiratory distress, he was maintained on non-mechanical ventilation with BiPap. The patient had a cytokine storm and was administered Tocilizumab, Remdesvir and intravenous Immunoglobulin therapy. The patient gradually improved and was continued on 8-10 litres of oxygen inhalation via non-rebreathing mask. He had no exacerbation of peripheral myasthenia syndromes like ptosis, extra-ocular muscle weakness, bulbar or limb weakness during hospitalization. Therapy for MG was not altered during hospitalization.

\section{Patient 3}

68-years-old male patient, diabetic and hypertensive was diagnosed as autoimmune MG fourteen months prior. His symptoms were well controlled on Tab Wysolone 20 daily, Tab Azathioprine $50 \mathrm{mg}$ twice daily and Tab Pyridostigmine $60 \mathrm{mg}$ thrice a day. He developed fever with cough and testing showed he was positive for SARS-CoV-2. He was admitted to the hospital on day 7 of onset

TABLE 1. Patients characteristics

\begin{tabular}{|c|c|c|c|}
\hline & Patient 1 & Patient 2 & Patient 3 \\
\hline Gender & Male & Male & Male \\
\hline Age (in years) & 71 & 63 & 68 \\
\hline $\begin{array}{l}\text { Duration of diagnosis of } \\
\text { MG }\end{array}$ & 8 months & 52 months & 14 months \\
\hline Antibody status & $\mathrm{AChR} \mathrm{Ab} \mathrm{+}$ & $\mathrm{AChR} \mathrm{Ab} \mathrm{+}$ & $\mathrm{AChR} \mathrm{Ab} \mathrm{+}$ \\
\hline $\begin{array}{l}\text { MGFA disease clinical } \\
\text { classification at time of } \\
\text { SARS-CoV-2 diagnosis }\end{array}$ & I & I & $\mathrm{I}$ \\
\hline thymoma-history/present & No & No & No \\
\hline MG treatment at home & $\begin{array}{l}\text { Tab Omnacortil } 20 \mathrm{mg} \text { daily, } \\
\text { Tab Pyridostigmine } 60 \mathrm{mg} \text { twice } \\
\text { daily, } \\
\text { Tab Mycophenolate Mofetil } 360 \\
\text { mg twice daily }\end{array}$ & $\begin{array}{l}\text { Tab Azathioprine } 50 \mathrm{mg} \\
\text { twice daily, } \\
\text { Tab Pyridostigmine } 60 \mathrm{mg} \\
\text { twice a day }\end{array}$ & $\begin{array}{l}\text { Tab Wysolone } 20 \mathrm{mg} \text { daily, Tab } \\
\text { Azathioprine } 50 \mathrm{mg} \text { twice daily, } \\
\text { Tab Pyridostigmine } 60 \mathrm{mg} \text { thrice } \\
\text { a day }\end{array}$ \\
\hline Pre-existing comorbidities & Hypothyroidism & Diabetes, Hypothyroidism & Diabetes, Hypertension \\
\hline $\begin{array}{l}\text { SARS-CoV-2 presenting } \\
\text { symptom }\end{array}$ & Fever, cough & Fever, cough, throat pain & $\begin{array}{l}\text { Fever followed by cough and } \\
\text { dyspnea }\end{array}$ \\
\hline $\begin{array}{l}\text { Treatment of SARS-CoV-2 } \\
\text { administered during } \\
\text { hospitalization } \\
\end{array}$ & Remdesvir & $\begin{array}{l}\text { Tocilizumab, Remdesvir, } \\
\text { iv Ig }\end{array}$ & Tocilizumab, iv Ig \\
\hline $\begin{array}{l}\text { ICU admission during } \\
\text { SARS-CoV-2 }\end{array}$ & No & Yes & Yes \\
\hline $\begin{array}{l}\text { Respiratory support } \\
\text { provided during } \\
\text { hospitalization }\end{array}$ & Intermittent oxygen inhalation & $\begin{array}{l}\text { High flow oxygen via non } \\
\text { re-breathing mask, followed } \\
\text { by BiPAP }\end{array}$ & $\begin{array}{l}\text { High flow oxygen via non re- } \\
\text { breathing mask, followed by } \\
\text { BiPAP, followed by Endotracheal } \\
\text { Intubation and prone mechanical } \\
\text { ventilation }\end{array}$ \\
\hline $\begin{array}{l}\text { Evidence of exacerbation } \\
\text { of MG }\end{array}$ & None & None & None \\
\hline Duration of hospitalization & 7 days & 36 days & 5 days \\
\hline Outcome of patient & Discharge & Discharge & Death \\
\hline
\end{tabular}


TABLE 2. Laboratory and radiological parameters

\begin{tabular}{|l|c|c|c|c|}
\hline Parameter & Normal Value & Patient 1 & Patient 2 & Patient 3 \\
\hline Hemoglobin (gm/dl) & $13-17$ & 12.5 & 13.2 & 14.1 \\
\hline White cell count (per cmm) & $4,000-11,000$ & 8200 & 5000 & 27,300 \\
\hline Neutrophils (\%) & $40-70$ & 81 & 87 & 94 \\
\hline Lymphocytes (\%) & $20-45$ & 11 & 9 & 4 \\
\hline Monocytes (\%) & $2-10$ & 8 & 4 & 2 \\
\hline Eosinophils (\%) & $1-6$ & 0 & 0 & 0 \\
\hline Basophills (\%) & $0-1$ & 0 & 0 & 0 \\
\hline Platelet count (no./cmm) & $1.5-4.5$ & 4.28 & 1.67 & 1.24 \\
\hline Mean corpuscular volume (fL) & $80-96$ & 89.6 & 88.7 & 87.2 \\
\hline Mean corpuscular hemoglobin (pg) & $27-34$ & 28.2 & 28.8 & 27.5 \\
\hline Creatinine (mg/dl) & $0.7-1.2$ & 1.05 & 0.87 & 1.1 \\
\hline Blood urea (mg/dl) & $15-40$ & 35 & 41 & 142 \\
\hline Prothrombin time (seconds) & 14 & 14 & 14 & 16 \\
\hline INR & & 1.0 & 1.0 & 1.1 \\
\hline $\begin{array}{l}\text { Activated partial-thromboplastin } \\
\text { time (seconds) }\end{array}$ & $28-32$ & 30 & 28 & 32 \\
\hline D-Dimer (mg/dl) & & & & \\
\hline Serum ferritin (ng/ml) & $<250$ & 398.3 & 345 & $\varnothing 1000$ \\
\hline Lactate Dehydrogenase (U/L) & $10-291$ & 459.1 & 281.9 & 721.0 \\
\hline ESR (mm/hour) & $313-618$ & 427 & 346 & 372 \\
\hline C-RP (mg/dl) & $0-9$ & 28 & 19 & 30 \\
\hline IL-6 (pg/ml) & $<0.6$ & 4.8 & 2.4 & 4.8 \\
\hline HbA1c (\%) & $0-6.4$ & 44.27 & 62.34 & 37.10 \\
\hline CT Chest & $3-6$ & 5.4 & 7 & 6.34 \\
\hline Percentage lung involvement & $25-30 \%$ & $80-85 \%$ & \\
\hline CORADS severity score & 6 & 6 & \\
\hline
\end{tabular}

of symptoms and needed high flow oxygen via non re-breathing mask for maintaining arterial oxygen saturation. The patient deteriorated rapidly while being hospitalized, developed hypoxemic respiratory failure and was administered intravenous Immunoglobulin at the dose of $400 \mathrm{mg} / \mathrm{kg} / \mathrm{day}$ for 3 days and subsequently succumbed to the disease. He was intubated and on mechanical ventilatory support on the day of death. He had no exacerbation of peripheral myasthenia syndromes like ptosis, extra-ocular muscle weakness, bulbar or limb weakness during hospitalization.

The clinical course of these patients was observed during hospitalization and the details of the same are mentioned in table 1 . The laboratory and $\mathrm{CT}$ chest findings of the patients are mentioned in table 2 .

None of the patients had an exacerbation of peripheral myasthenia syndromes like ptosis, extra-ocular muscle weakness, bulbar or limb weakness during hospitalization. Therapy for MG was not altered during hospitalization for any of the patients.
Depending on the symptoms, level of the serum inflammatory markers and CT chest findings, specialized therapies were administered to the patients. There was no relation of ultimate patient outcome with the duration of MG symptoms, previous therapy of $\mathrm{MG}$, and the pre-existing comorbidities. Further, the outcome of these patients depends on the levels of serum inflammatory markers, percentage of lung involvement and CT severity score for SARS-CoV-2.

\section{DISCUSSION}

Infections are a known common trigger for myasthenic exacerbations [4]. Theoretically, there is a higher risk of experiencing severe manifestations of SARS-CoV-2 due to the common use of immunosuppressive drugs and potential respiratory failure in relation to respiratory muscle weakness. Additionally, experimental therapies for SARS-CoV-2 like azithromycin and hydroxychloroquine may also trigger a myasthenic exacerbation $[5,6]$.

In our patients, we had no exacerbation of myasthenic symptoms which is a very noteworthy ob- 
servation, as respiratory infections are known to be the most common precipitant of respiratory failure and crisis in myasthenia patients [7].

Previous use of steroids plus immunosuppressive therapies did not seem to determine an unfavorable outcome in our patients. Though immuno-suppressed patients could be at a higher risk for a more severe COVID-19 course, growing evidence shows that immunosuppression might play a protective role, reducing the immune response that leads to an inflammatory cytokine storm and to clinical deterioration $[8,9]$.

Conflict of interest: none declared

Financial support: none declared

\section{REFERENCES}

1. Garg R, Jain R, Sodani A, et al. Neurological Symptoms as Initial Manifestation of Covid-19 - An Observational Study. Ann Indian Acad Neurol. 2020;23(4):482-486

2. Li Y, Li M, Wang M, Zhou Y, Chang J, Xian Y, Wang D, Mao L, Jin H, Hu B. Acute cerebrovascular disease following COVID-19: a single center, retrospective, observational study. Stroke Vasc Neurol. 2020 Sep;5(3):279-284

3. Mao L, Jin H, Wang M, Hu Y, Chen S, He Q et al. Neurologic Manifestations of Hospitalized Patients With Coronavirus Disease 2019 in Wuhan, China. JAMA Neurol. 2020;77(6):683-90.

4. Gummi RR, Kukulka NA, Deroche CB, Govindarajan R. Factors associated with acute exacerbations of myasthenia gravis. Muscle Nerve. 2019;60:693-699.

5. Gilhus NE, Romi F, Hong Y, Skeie GO. Myasthenia gravis and infectious disease. J Neurol. 2018;265:1251-58.

\section{CONCLUSIONS}

Our series is limited by the small number of patients and short duration of follow-up, which did not include the postinfectious period, a time of risk for myasthenic exacerbation. Larger and longer observations are needed to more fully understand: whether patients with $\mathrm{MG}$ face special risks from SARS-CoV-2 infection or treatments, whether baseline therapies impact risk and best principals for management and treatment of SARS-CoV-2 in patients with MG.

6. Jallouli M, Saadoun D, Eymard B, et al. The association of systemic lupus erythematosus and myasthenia gravis: a series of 17 cases, with a special focus on hydroxychloroquine use and a review of the literature. J Neurol. 2012;259(7):1290-97.

7. Wendell LC, Levine JM. Myasthenic crisis. Neurohospitalist. 2011 Jan;1(1):16-22.

8. Li H, Liu L, Zhang D, Xu J, Dai H, Tang N, et al. SARS-CoV-2 and viral sepsis: observations and hypotheses. Lancet. 2020; 395:1517-20.

9. Mehta P, McAuley DF, Brown M, Sanchez E, Tattersall RS, Manson JJ, et al. COVID-19: consider cytokine storm syndromes and immunosuppression. Lancet. 2020;395:1033-4. 